\title{
Correction of Dialysis-Induced Metabolic Alkalosis
}

\author{
Assad Mohammedzein, MD; and Tarek Naguib, MD
}

\begin{abstract}
Normal saline solution infusion with concurrent removal by ultrafiltration successfully corrected pretreatment metabolic alkalosis when other measures were inadequate for a patient on dialysis.
\end{abstract}

\begin{abstract}
Assad Mohammedzein is a Resident Physician in the Department of Internal Medicine; and Tarek Naguib is an Associate Professor, Department Chair, Internal Medicine, Division of Nephrology; both at Texas Tech

University Health Science Center and Thomas E.

Creek Department of Veterans Affairs Medical Center in Amarillo, Texas. Correspondence: Assad Mohammedzein (assad.mohammedzein@ hhchealth.org)
\end{abstract}

Fed Pract. 2021;38(4). Published online

April 12, 2021.

doi:10.12788/fp.0116
$\mathrm{M}$ etabolic alkalosis, a disorder that causes elevations in serum bicarbonate and arterial $\mathrm{pH}$, is a common metabolic abnormality found in nearly half of hospitalized patients but is rare in patients with end-stage renal disease (ESRD) on hemodialysis (HD) during the pretreatment state. The problem seems to arise due to a high rate of older patients with multiple comorbidities and malnutrition who are undergoing HD. Metabolic alkalosis is associated with increased morbidity and mortality. In this report, we present a case of metabolic alkalosis, describe an innovative approach to manage metabolic alkalosis in the dialysis population, and review the pathophysiology.

\section{CASE PRESENTATION}

A 63-year-old female with emphysema, diabetic nephropathy, and ESRD on regular HD for 2 months by a tunneled subclavian vein catheter was admitted with 2 weeks of orthopnea and leg swelling. The review of systems was negative for chest pain, cough, wheeze, or sputum production. She was a former smoker with no alcohol or drug misuse. The patient was taking carvedilol $25 \mathrm{mg}$ daily, furosemide $20 \mathrm{mg}$ twice daily, basal insulin premeal, lisinopril $40 \mathrm{mg}$ daily, pantoprazole $40 \mathrm{mg}$ daily, calcium carbonate $400 \mathrm{mg} 3$ times daily, ferrous sulphate $325 \mathrm{mg}$ daily, and a vilanterol/tiotropium inhaler once daily. Her dialysate outpatient prescription included sodium $140 \mathrm{mEq} / \mathrm{L}$, potassium $2 \mathrm{mEq} / \mathrm{L}$, calcium $2.5 \mathrm{mEq} / \mathrm{L}$, and bicarbonate $36 \mathrm{mEq} / \mathrm{L}$. Our dialysis unit used NaturaLyte dry pack for bicarbonate dialysis.

The patient appeared tachypneic with 26 respirations/min, oxygen satura- tion of $89 \%$ on room air, which improved to $94 \%$ on a 2 L nasal cannula. Her heart rate was 89 beats/min, blood pressure was $129 / 72 \mathrm{~mm} \mathrm{Hg}$, and body mass index was 21.2. The physical examination revealed jugular venous distension, lung crackles, reduced air entry, and pedal edema. Muscle wasting was noted in the arms and thighs. The tunnel catheter did not appear infected.

The patient's blood work showed sodium, 136 (reference, 132-140) mmol/L; potassium, 4.3 (reference, 3.5-5.0) $\mathrm{mmol} / \mathrm{L}$; chloride, 89 (reference, 98-111) $\mathrm{mmol} / \mathrm{L}$; total $\mathrm{CO}_{2}$, 36 (reference, 24-28) mEq/L; blood urea nitrogen, 21 (reference, 7-21) mg/dL; creatinine 3.4 (reference, 0.5-1.4) $\mathrm{mg} / \mathrm{dL}$; and albumin, 2.7 (reference, $3.7-5.0$ ) mg/dL. Arterial gases showed $\mathrm{pH}, 7.56$ (reference, 7.35-7.45), partial $\mathrm{CO}_{2}, 47$ (reference, 35-45) mm Hg; bicarbonate, 42 (reference, 22-26) $\mathrm{mEq} / \mathrm{L}$; partial $\mathrm{O}_{2}, 54$ (reference, 75 to 100 ) $\mathrm{mm} \mathrm{Hg}$. Brain natriuretic peptide was 2,800 (normal, $<100$ ) $\mathrm{pg} / \mathrm{mL}$ with a normal troponin. X-rays showed pulmonary congestion and bilateral pleural effusions that were transudative on fluid analysis. An echocardiogram showed ejection fraction of 20 to $25 \%$ with normal valves (baseline ejection fraction of $60 \%$ $65 \%)$. A coronary arteriogram revealed severe nonischemic cardiomyopathy.

\section{Treatment}

To reduce bicarbonate levels, $3 \mathrm{~L}$ of normal saline solution were infused prefilter during $\mathrm{HD}$, and ultrafiltration (UF) of $4.5 \mathrm{~L}$ achieved a net UF of $-1.5 \mathrm{~L}$ over 3.5 hours on lower dialysate bicarbonate $(30 \mathrm{mEq} / \mathrm{L})$. Good catheter flow was achieved with a blood flow rate of $350 \mathrm{~mL} / \mathrm{min}$ and a dialysate flow of $700 \mathrm{~mL} / \mathrm{min}$. Venous blood gases and basic 
serum metabolic panels were obtained throughout the first HD session (Table 1). Improvement in $\mathrm{pH}$ from 7.5 to 7.43 and in total $\mathrm{CO}_{2}$ from 36 to $30 \mathrm{mEq} / \mathrm{L}$ were noted after the treatment. Subsequently, we used the same membrane (Optiflux F160NRe) for 2 consecutive daily treatments to remove excess fluid and prevent worsening alkalosis using the same minimal bicarbonate bath, but no further normal saline solution was given.

\section{Outcome}

Volume overload was controlled as needed with UF. The bicarbonate did not drop after the second HD session, suggesting low organic acid production in the intradialytic period. By shortening the duration of dialysis to 3 hours and improving nutritional intake, we achieved dry weight, and the patient was discharged home with a total $\mathrm{CO}_{2}$ of $25 \mathrm{mEq} / \mathrm{L}$. Outpatient dialysis sessions were arranged to run at shorter duration (3 hours compared with 3.5 hours) and use low bicarbonate dialysate. The patient was admitted several times afterward for acute decompensated heart failure, but in all those admissions, her bicarbonate was in the normal-to-high range, between 23 and $30 \mathrm{mEq} / \mathrm{L}$.

\section{DISCUSSION}

Metabolic alkalosis is relatively rare in ESRD patients on HD. Particularly in the predialysis period, but with the growing number of older patients undergoing HD and the aggressive treatment of acidosis with relatively higher buffer concentrations; there has been an increase in the incidence of metabolic alkalosis in patients on HD. In the Fresenius Medical Care (FMC) prevalent HD patient study, predialysis bicarbonate levels have increased overtime from a mean (SD) 22.9 (3.1) $\mathrm{mEq} / \mathrm{L}$ in 2004 to a mean (SD) 24.1 (3.5) $\mathrm{mEq} / \mathrm{L}$ in September 2011, with $25 \%$ of patients $>26.0 \mathrm{mEq} / \mathrm{L}$ compared with only $6 \%$ in $2004 .{ }^{1}$ The condition has been associated with cardiac arrhythmia, intradialytic hypocalcemia, hypokalemia, hypercapnia, hypoxia, accelerated hypertension, and seizure. ${ }^{2-4}$ Metabolic alkalosis may be associated with increased mortality. ${ }^{5-7}$ However, the effect dissipated after adjusting for inflammation and nutritional status. ${ }^{6}$

Our patient had primary metabolic alkalosis evident by her high $\mathrm{pH}$ of 7.56 and
TABLE 1 First Dialysis Session Results

\begin{tabular}{l|ccc} 
Components & Before & $\begin{array}{c}\text { Hemodialysis } \\
\text { During }\end{array}$ & After \\
\hline $\mathrm{pH}$ & 7.50 & 7.47 & 7.43 \\
\hline $\mathrm{PCO}_{2}, \mathrm{~mm} \mathrm{Hg}$ & 42 & 48 & 47 \\
\hline Total $\mathrm{CO}_{2}, \mathrm{mEq} / \mathrm{L}$ & 36 & 36 & 30 \\
\hline Sodium, $\mathrm{mmol} / \mathrm{L}$ & 137 & 137 & 136 \\
\hline Chloride, $\mathrm{mmol} / \mathrm{L}$ & 91 & 100 & 101
\end{tabular}

high total $\mathrm{CO}_{2}$ of $36 \mathrm{mEq} / \mathrm{L}$. The serum total $\mathrm{CO}_{2}$ reflects the metabolic status more accurately than the blood gas bicarbonate, which is prone to calculation error by the Henderson-Hasselbalch equation. Her respiratory compensation for the metabolic alkalosis was appropriate, with an increase of arterial $\mathrm{PaCO}_{2}$ to $47 \mathrm{~mm} \mathrm{Hg}$ (expected $\left.\mathrm{PaCO}_{2}=40+0.7\left[\mathrm{HCO}_{3}-24\right]=48.4\right)$. She had normal baseline $\mathrm{PaCO}_{2}$ in the weeks prior to admission. Due to lack of residual urine output, $<50 \mathrm{~mL} / \mathrm{d}$, her metabolic alkalosis could not be attributed to the generation of bicarbonate by the kidneys, or ameliorated by dumping of excess bicarbonate, which explained why her metabolic alkalosis was severe. On the other hand, respiratory distress may have hindered the appropriate $\mathrm{CO}_{2}$ retention.

In patients with ESRD on HD who have no residual urine output, causes of metabolic alkalosis are limited to loss of net acid or gain of alkali through the gastrointestinal tract; our patient had none of these. Similarly, all renal causes of metabolic alkalosis are not applicable to our patient, including mineralocorticoid excess and contraction alkalosis. In patients with preserved kidney function, loop diuretics can induce alkalosis through enhanced tubular absorption of $\mathrm{HCO}_{3}$. While acetazolamide can mitigate this scenario by blocking carbonic anhydrase in the luminal border of the collecting ducts resulting in excretion of bicarbonate in the urine, our patient had negligible urine output despite being on furosemide $20 \mathrm{mg}$ twice daily, making this an unlikely cause.

Severe metabolic alkalosis in dialysis patients has been reported with cocaine use, pica ingestion, and citrate load as in plasma exchange, massive transfusions, and 
TABLE 2 Contents of Acid Concentrates by Manufacturera

\begin{tabular}{llcccc} 
Manufacturers & $\begin{array}{l}\text { Acid } \\
\text { Concentrate }\end{array}$ & $\begin{array}{c}\text { Acetic acid, } \\
\mathbf{m E q} / \mathbf{L}\end{array}$ & $\begin{array}{c}\text { Acetate, } \\
\mathbf{m E q} / \mathbf{L}^{\mathrm{b}}\end{array}$ & $\begin{array}{c}\text { Citric acid, } \\
\mathbf{m E q} / \mathbf{L}^{\mathrm{b}}\end{array}$ & $\begin{array}{c}\text { Sum of Acetic Acid, } \\
\text { Acetate, and Citric Acid } \\
\text { (mEq/L) }\end{array}$ \\
\hline Fresenius & NaturaLyte & 4 & - & - & 4 \\
Medical Care & $\begin{array}{l}\text { GranuFlo } \\
\text { Citrasate }\end{array}$ & 4 & 4 & - & 8 \\
\hline Minntech & - & 0.3 & 2.4 & 2.7 \\
& Centrisol & 4 & - & - & 4 \\
\hline \multirow{2}{*}{ Diasol } & Renasol & 4 & - & - & 4 \\
& Diasol & 4 & - & - & 4 \\
& Dryasol & 4 & - & - & 4
\end{tabular}

Adapted from Fresenius Medical Care North America Bicarbonate Dialysis Update. ${ }^{1}$

${ }^{a}$ All available dialysates have either acetic acid, acetate, citric acid or combinations of these elements.

${ }^{b}$ Actual value may vary slightly depending on postreaction bicarbonate and sodium settings.

regional anticoagulation. ${ }^{2,8-11}$ Although calcium carbonate intake can contribute to alkalosis, her small daily dose of $1,200 \mathrm{mg}$ contains approximately $12 \mathrm{mEq}$ of carbonate, which is not a significant contributor to the alkalosis.

With all other causes excluded, the metabolic alkalosis in our patient is presumed to result from the bicarbonate-rich dialysate. Since the majority of patients with ESRD are acidotic before dialysis, the dialysate bicarbonate is set at a higher than normal physiologic level to bring the $\mathrm{pH}$ close to or even higher than normal after dialysis. The patient had been dialyzed with NaturaLyte as an outpatient, which was set at the dialysis unit default mode of $36 \mathrm{mEq} / \mathrm{L}$. This form of alkalosis has been reported to peak immediately after treatment but in most patients returns to the predialysis acidotic state due to endogenous acid production. ${ }^{1,4,12}$ Normally, muscles play a significant role in buffering excess bicarbonate in patients with nonfunctioning kidneys; hence, malnutrition with muscle wasting tends to propagate and maintain alkalosis, as in our patient.

Managing alkalosis in patients on dialysis can be challenging and is often directed at identifying potential causes like overzealous bicarbonate dialysate and addressing comorbidities, especially malnutrition. ${ }^{6,7}$ Bicarbonate delivery can be set on dialysis machines as low as $20 \mathrm{mEq} / \mathrm{L}$. However, the reliability of correcting serum bicarbonate by adjusting bicarbonate-based dialysis products is in question as these products deliver additional buff- ering capacity through mixing and metabolism of acetate, acetic acid, or citric acid (Table 2).

We infused a high volume of sodium chloride during dialysis to create hyperchloremic metabolic acidosis while removing the volume by UF, thereby eliminating more bicarbonate by convection. Normal saline has a pH of 5.5 and a chloride of $154 \mathrm{mmol} / \mathrm{L}$. We have compensated for an inherent lack of flexibility in HD as it is currently practiced: dialysates are virtually all deliberately alkaline because most of the patients coming to HD have varying magnitudes of metabolic acidosis and acidemia. The dialysate concentrate that dilutes to a bicarbonate level of $30 \mathrm{mEq} / \mathrm{L}$ would have only a modest effect against this magnitude of metabolic alkalosis that this patient had at dialysis. We have compensated for this structural inadequacy of current HD by repairing the patient's severe hypochloremic metabolic alkalosis by infusing a hyperchloremic sodium chloride solution and dialyzing off the excess sodium bicarbonate. This is the logical inverse of what usually happens in the severely acidotic patients seen prior to dialysis: dialyzing off an excess of normal saline and repairing the metabolic acidosis by transfer-in of sodium bicarbonate from the dialysate.

Fresenius Medical Care, which provides most HD machines and fluids in the United States, created charts to show the approximate degree that each contributes as additional buffer. That was in response to a class action lawsuit for metabolic alkalosis 
due to overdelivery of bicarbonate that resulted in alleged cardiac arrests in patients with HD. ${ }^{13}$ Their report cast doubt on the ability of a lower bicarbonate bath to correct metabolic alkalosis in a predictable fashion. ${ }^{1}$ We accordingly showed that normal saline delivery is a reliable option to promptly lower serum bicarbonate level. However, this is a temporary measure and long-term bicarbonate delivery during dialysis needs to be addressed.

Huber and Gennari demonstrated success in reducing severe alkalosis in patients with ESRD due to vomiting with the use of $\mathrm{HCO}_{3}$ bath of $30 \mathrm{mEq} / \mathrm{L} .{ }^{14}$ In their report, the calculated bicarbonate dropped from 94 to $39 \mathrm{mEq} / \mathrm{L}$; after 3 hours of $\mathrm{HD}$, their patient also was receiving $2 \mathrm{~L}$ of an isotonic saline infusion daily. These observations suggest that lowering bicarbonate in the bath is effective in much more severe cases than ours, and even then, extra measures are needed to bring it down to desirable levels. In the early days, some health care providers used a specially prepared high-chloride (123 mEq/L) and low-acetate dialysate $(18 \mathrm{mEq} / \mathrm{L})$, which increased serum chloride and hydrogen ion concentrations and decreased the serum bicarbonate concentration compared with those in commercially available high-acetate dialysate (containing $37 \mathrm{mEq} / \mathrm{L}$ acetate and $104 \mathrm{mEq} / \mathrm{L} \mathrm{Cl}){ }^{15}$ However, this method requires special preparation of dialysate. Oral potassium chloride also was used to correct metabolic alkalosis, but the risk of potassium overload precludes this approach in patients with ESRD. ${ }^{16}$

Likewise, adding oral sodium chloride risks causing volume overload, especially in patients with cardiomyopathy; it may increase thirst, resulting in interdialytic excess volume gains. ${ }^{17}$ In our patient, respiratory compensation took place by correcting pulmonary congestion by UF, and the gentle bicarbonate removal in addition to boosting chloride levels promptly improved the metabolic alkalosis.

Notably adequate volume control achieved by HD in persons with small muscle mass and severe cardiomyopathy can require longer treatment duration than required to achieve adequate clearance. Accordingly, more bicarbonate loading can take place, causing metabolic alkalosis. This problem is compounded by the potential overdelivery of bicarbonate than that entered by the physician's order. ${ }^{1}$

\section{CONCLUSIONS}

Attention should be paid to detect elevated predialysis serum bicarbonate levels in ESRD patients on $\mathrm{HD}$, especially those with values above $27 \mathrm{mmol} / \mathrm{L}$ due to higher mortality. ${ }^{6,7}$ Treatment of these patients is more challenging than for those who are acidotic predialysis, especially when alkalosis is compounded by malnutrition. Mitigation of this problem is achieved by using a lower bicarbonate bath and the shortest effective dialysis duration that achieves adequate clearance. Poor clearance also deleteriously affects patient nutrition and well-being. We have shown that normal saline solution infusion with concurrent removal by UF can correct pretreatment metabolic alkalosis when other measures are inadequate.

\section{Author disclosures}

The authors report no actual or potential conflicts of interest with regard to this article.

\section{Disclaimer}

The opinions expressed herein are those of the authors and do not necessarily reflect those of Federal Practitioner, Frontline Medical Communications Inc., the US Government, or any of its agencies. This article may discuss unlabeled or investigational use of certain drugs. Please review the complete prescribing information for specific drugs or drug combinations - including indications, contraindications, warnings, and adverse effects-before administering pharmacologic therapy to patients.

\section{References}

1. Fresenius Medical Care North America. Bicarbonate dialysis update. July 2012. Accessed May 14, 2018. http:// www.renalweb.com/writings/alkalosis/FMC\%20Jul\%20 25\%202012.pdf

2. Rho M, Renda J. Pica presenting as metabolic alkalosis and seizure in a dialysis patient. Clin Nephrol. 2006;66(1):71-73. doi:10.5414/cnp66071

3. Bear R, Goldstein M, Phillipson E, et al. Effect of metabolic alkalosis on respiratory function in patients with chronic obstructive lung disease. Can Med Assoc J. 1977;117(8):900-903.

4. Javaheri $\mathrm{S}$, Kazemi $\mathrm{H}$. Metabolic alkalosis and hypoventilation in humans. Am Rev Respir Dis. 1987;136(4):10111016. doi:10.1164/ajrccm/136.4.1011

5. Yamamoto T, Shoji S, Yamakawa T, et al. Predialysis and postdialysis $\mathrm{pH}$ and bicarbonate and risk of all-cause and cardiovascular mortality in long-term hemodialysis patients. Am J Kidney Dis. 2015;66(3):469-478. doi:10.1053/j.ajkd.2015.04.014

6. Wu DY, Shinaberger CS, Regidor DL, McAllister CJ, Kopple JD, Kalantar-Zadeh K. Association between serum bicarbonate and death in hemodialysis 
patients: is it better to be acidotic or alkalotic? Clin J Am Soc Nephrol. 2006;1(1):70-78. doi:10.2215 /CJN.00010505

7. Bommer J, Locatelli F, Satayathum S, et al. Association of predialysis serum bicarbonate levels with risk of mortality and hospitalization in the Dialysis Outcomes and Practice Patterns Study (DOPPS). Am J Kidney Dis. 2004;44(4): 661-671. doi:10.1053/j.ajkd.2004.06.008

8. Diskin CJ, Stokes TJ, Dansby LM, Radcliff L, Carter TB. Recurrent metabolic alkalosis and elevated troponins after crack cocaine use in a hemodialysis patient. Clin Exp Nephrol. 2006;10(2):156-158. doi:10.1007/s10157-006-0414-y

9. Ostermann ME, Girgis-Hanna Y, Nelson SR, Eastwood JB. Metabolic alkalosis in patients with renal failure. Nephrol Dial Transplant. 2003;18(11):2442-2448. doi:10.1093/ndt/gfg333

10. Rahilly GT, Berl T. Severe metabolic alkalosis caused by administration of plasma protein fraction in endstage renal failure. N Engl J Med. 1979;301(15):824-826. doi:10.1056/NEJM197910113011506

11. Panesar M, Shah N, Vaqar S, et al. Changes in serum bicarbonate levels caused by acetate-containing bicarbonate-buffered hemodialysis solution: an observationa prospective cohort study. Ther Apher Dial. 2017;21(2):157165. doi:10.1111/1744-9987.12510
12. Noh U-S, Yi J-H, Han S-W, Kim H-J. Varying dialysate bicarbonate concentrations in maintenance hemodialysis patients affect post-dialysis alkalosis but not pre-dialysis acidosis. Electrolyte Blood Press. 2007;5(2):95-101. doi:10.5049/EBP.2007.5.2.95

13. Perriello B. Fresenius, plaintiffs ask for more time for $\$ 250 \mathrm{~m}$ settlement in dialysate cases. Published March 4, 2016. Accessed May 14, 2018. https://www.massdevice com/fresenius-askes-judge-time-250m-settlement -dialysate-cases

14. Huber L, Gennari FJ. Severe metabolic alkalosis in a hemodialysis patient. Am J Kidney Dis. 2011;58(1):144-149. doi:10.1053/j.ajkd.2011.03.016

15. Swartz RD, Rubin JE, Brown RS, Yager JM, Steinman TI, Frazier HS. Correction of postoperative metabolic alkalosis and renal failure by hemodialysis. Ann Intern Med. 1977;86(1):52-55. doi:10.7326/0003-4819-86-1-52

16. Rosen RA, Julian BA, Dubovsky EV, Galla JH, Luke RG. On the mechanism by which chloride corrects metabolic alkalosis in man. Am J Med. 1988;84(3, pt 1):449-458. doi:10.1016/0002-9343(88)90265-3

17. Hirakawa Y, Hanafusa N, Nangaku M. Correction of metabolic alkalosis and elevated calcium levels by sodium chloride in a hemodialysis patient with inadequate chloride intake. Ther Apher Dial. 2016;20(1):86-87. doi:10.1111/1744-9987.12335

\section{NOW AVAILABLE IN THE APP AND ONLINE}

\section{TOPICS COVERED}

IN THIS SPECIAL ISSUE INCLUDE:

- Women's Health

- Neurologic Disorders

- Diabetes Mellitus

- Infectious Disease

- And More

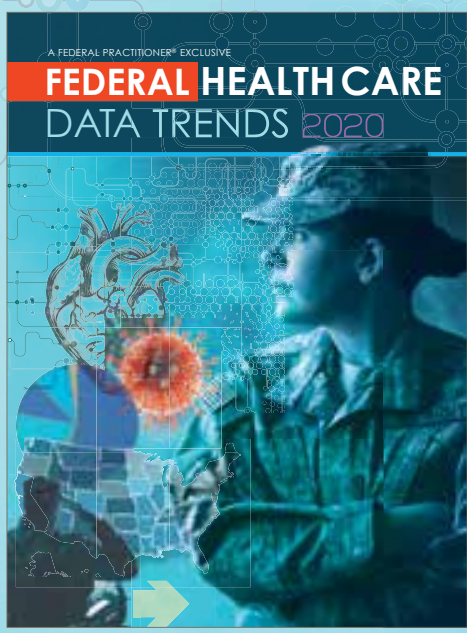

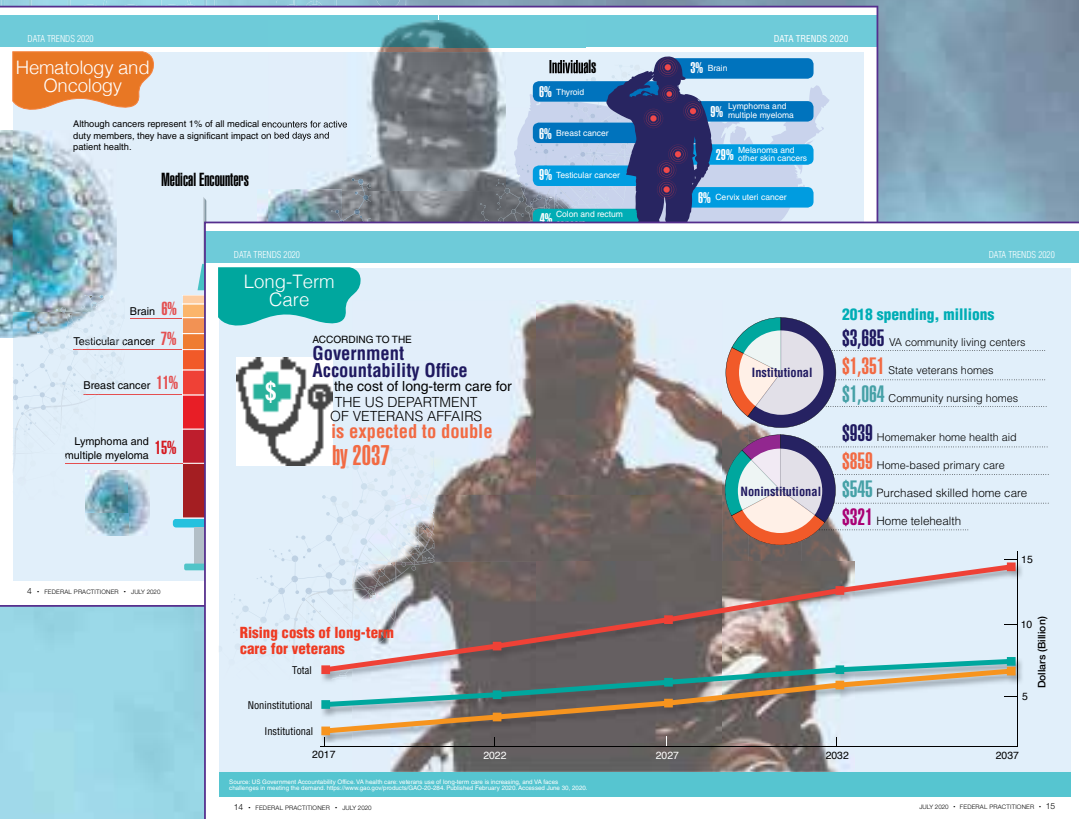

www.mdedge.com/fedprac 